\title{
Thermodynamic analysis of a dual power-hydrogen production system based on chemical-looping combustion
}

\author{
Álvaro Urdiales \\ Department of Energy Engineering \\ Universidad Politécnica de Madrid, Madrid, Spain \\ e-mail: alvaro.urdiales.montesino@alumnos.upm.es \\ Ángel Jiménez*, Susana Sánchez, Celina González \\ Department of Energy Engineering \\ Universidad Politécnica de Madrid, Madrid, Spain \\ e-mail: a.jimenez@upm.es
}

\begin{abstract}
Chemical-looping hydrogen generation (CLHG) is a chemical-looping combustion variant that allows simultaneous production of power and hydrogen. A thermodynamic analysis from the exergy method point of view of an integrated syngas-fueled CLHG cycle is carried out with the aim of contributing to the conceptual understanding and development of CLHG systems. The cycle working point is optimized in a range of conditions. The proposed system shows a very interesting potential for power, hydrogen and process heating coproduction with high efficiency.
\end{abstract}

\section{KEYWORDS}

Chemical-looping combustion; dual power-hydrogen generation; trigeneration; gas turbine system; exergy analysis; efficient power generation; alternative combustion systems

\section{INTRODUCTION}

The global warming phenomenon that is currently taking place should be mitigated by reducing the emissions of greenhouse gases (GHG) to atmosphere. As it is well known, a large part of the anthropogenic GHG emissions is due to combustion of fossil fuels in transport and power generation. Until a transition to the use of new clean sources of energy is eventually achieved, a possible option for reducing the impact of power generation from fossil fuels is the carbon capture and storage (CCS) from the flue gases. A review on several alternatives for this purpose can be found in [1]. Nevertheless, the main available techniques (pre-combustion carbon capture [2], post-combustion carbon capture [3] and oxy-combustion [4]) imply severe energy penalties related to de difficulty of separation of pure gases from a mixture of them. The excessive increment of the power production cost makes very hard in practice the implementation of these kinds of steps.

A promising different approach that allows for carbon capturing without large energy consumption was first proposed by Ishida and Jin [5], and subsequently patented in USA [6]. Chemical-looping combustion (CLC) is a thermochemical process where fuel oxidation is carried out through an intermediate agent that actuates as oxygen carrier between two separated reactors: i) a fuel reactor, where the oxygen carrier is reduced oxidizing the fuel,

\footnotetext{
* Corresponding author
} 
and ii) an air reactor, where the oxygen carrier is oxidized in air. Overall, the system carries out the same chemical transformation as a conventional combustion, with the fundamental advantage of segregating the oxidation products $\mathrm{CO}_{2}$ and $\mathrm{H}_{2} \mathrm{O}$ into an output flow not diluted in air, where the only non-condensable gas is $\mathrm{CO}_{2}$. Interesting research has been carried out in the application of CLC to gas turbine systems for power generation by several authors. Ref. [7] gives an analysis of a gas-steam combined cycle fired by methane with CLC, [8] provides a pre-commercial evaluation of a CLC combined cycle scaled plant. Also CLC gas turbine systems based on alternative fuels such as methanol have been proposed [9]. In Ref. [10] an interesting exergy analysis of a CLC gas turbine system considering methane and syngas as fuels and nickel and iron oxides as oxygen carriers is given. Some other recent works focus on CLC combustion of syngas in gas turbine systems [11] exploring a possible integration of combined cycle power plants with carbon or biomass gasification. A complete integrated gasification combined cycle power plant based on CLC is analyzed in [12].

An attractive variation of CLC is the so-called chemical-looping hydrogen generation (CLHG). An interesting theoretical exploration of CLHG can be found in [13]. The main idea is to split the combustion into three stages instead of into two, introducing a third reactor in the chemical looping, as shown in Fig. 1. The complete reduction of the oxygen carrier takes places in the fuel reactor (FR), and its oxidation takes place in two steps, partially in a steam reactor (SR) and completely at the air reactor (AR). Some heat is released in the AR, which can be introduced in a power generation cycle, and also a mixture of steam and hydrogen is obtained as output of the SR. Pure and already pressurized hydrogen is got after water condensation. The outcome of the FR is a blend of $\mathrm{H}_{2} \mathrm{O}$ and $\mathrm{CO}_{2}$ so the carbon dioxide can be easily separable as well. This way, both power and hydrogen can be generated simultaneously from fuel and the resulting carbon dioxide can be sequestrated with a high potential of energy savings.

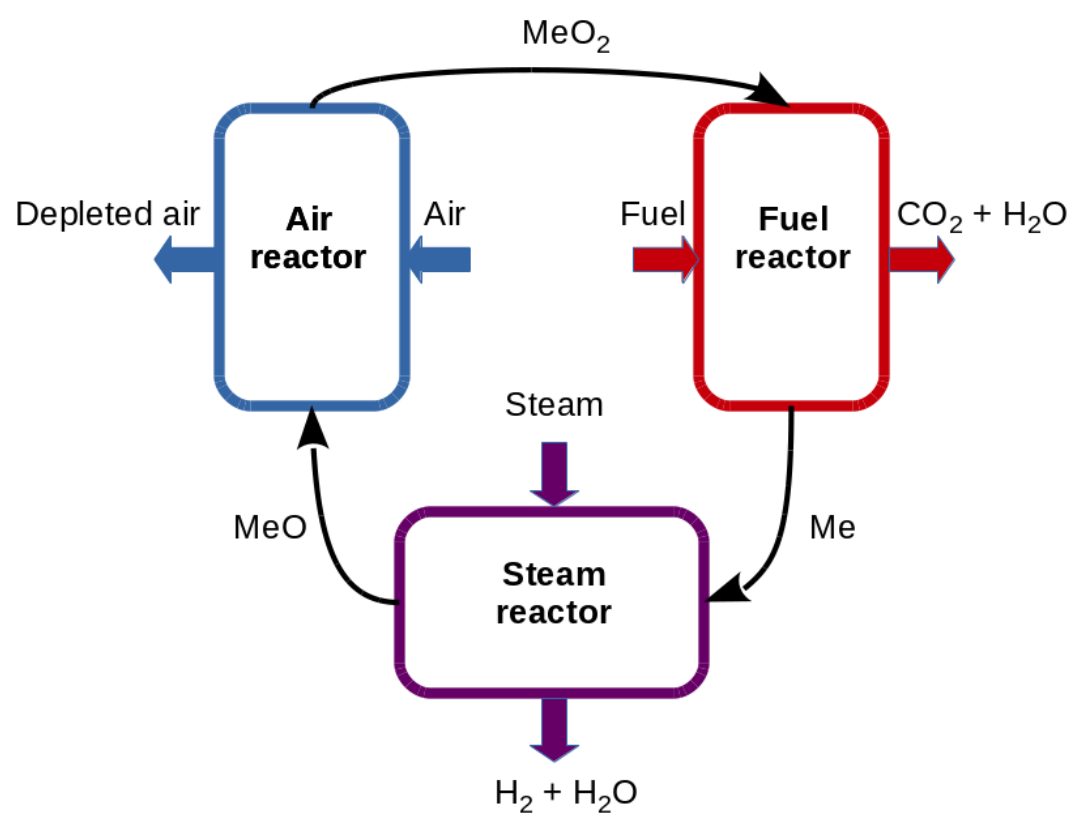

Figure 1. Representation of the CLHG concept

In this context, a combination of the two previous ideas, i.e. the integrated gasification of coal upstream to a syngas-fueled gas turbine system, and the CLHG concept itself, is explored 
very convincingly by reference [14]. A complex system is modeled and both, energy and exergy analysis are provided. A similar approach is followed in the present work. Primarily, the exergy method is followed here to carry out a thermodynamic analysis of a CLHG system fuelled by syngas obtained from coal gasification. Several thermodynamic aspects are taken into account for study, in particular the influence of the thermodynamic conditions on the behavior of the main cycle components, the complex energy balances and chemical equilibrium in reactors and the exergy flows in the system, among others. It is intended to contribute to the conceptual understanding and development of combined power and hydrogen chemical looping generation with high efficiency.

\section{PROPOSED CLHG SYSTEM}

\section{Cycle description and operating conditions}

The proposed CLHG system is schematically presented in Fig. 2. The most important components of this system are enumerated as following:

- Two gas turbines. GT1 is the main gas turbine and generates power from an expansion of the depleted air stream. Additionally a second gas turbine GT2 is integrated to expand the pressurized stream containing $\mathrm{H}_{2} \mathrm{O}$ and $\mathrm{CO}_{2}$ obtained from the FR.

- A heat recovery steam generator (HRSG) takes the streams for the gas turbines output for additional power production in a steam turbine cycle (ST). This part of the system is considered conventional. It has been modeled in a simplified way instead of resolving the details.

- The three looping reactors FR, SR and AR. They are pressure-linked, since the oxygen carrier describes a complete loop. The SR is fed by a steam extraction from the HRSG at the reactors pressure.

- A compression stage for carbon dioxide and hydrogen streams. Both of them are obtained in a blend with water, so previously to the compression condensation of water is required.

- Similarly to the $\mathrm{H}_{2} \mathrm{O} / \mathrm{CO}_{2}$ stream, the $\mathrm{H}_{2} \mathrm{O} / \mathrm{H}_{2}$ stream could be reheated and expanded in a third gas turbine to obtain some extra work. This is the case in the CLHG system proposed by [14]. On the contrary, here we have preferred to consider a trigeneration scheme where some process heating is supplied by the $\mathrm{H}_{2} \mathrm{O} / \mathrm{H}_{2}$ stream. This prior to the water condensation stage.

There are some other components: air compressor (AC), fuel compressor (FC), carbon dioxide compressors (CDC), hydrogen compressors (HC) (two-stage compression is assumed in both cases), air filter (AF) and several condensers for water extraction from gaseous streams.

The cycle parameters are summarized next: Ambient temperature $25^{\circ} \mathrm{C}(298.15 \mathrm{~K})$, ambient pressure $1 \mathrm{~atm}(1.01325 \mathrm{bar})$ and air molar composition resulting from a value $60 \%$ relative humidity (RH), $\mathrm{N}_{2} 77.26 \%, \mathrm{O}_{2} 20.78 \%, \mathrm{H}_{2} \mathrm{O} 1.01 \%$, Ar $0.93 \%$ and $\mathrm{CO}_{2} 0.03 \%$. Pressure drop at the air filter 0.01 bar. Isentropic efficiency of all compressors 0.845 . Isentropic efficiency of gas turbines 0.895 . Syngas input conditions are taken as provided by the gasifier after cleanup, $153.4{ }^{\circ} \mathrm{C}(426.58 \mathrm{~K})$ and 27.24 bar [15]. A $4 \%$ pressure drop in each reactor is adopted. Heat loses of $0.5 \%$ of the fuel's lower heating value (LHV) in the AR and $0.2 \%$ in both, FR and SR. Pressure drop of $3.5 \%$ in the HRSG. Temperature of exhaust air at HRSG outlet is the lowest among dew point and $90{ }^{\circ} \mathrm{C}(363.15 \mathrm{~K})$. Compression pressure for carbon dioxide and hydrogen has been set to $100 \mathrm{bar}$, allowing storage or transport as high-density supercritical fluid. These operating conditions are considered to be within typical ranges in combined cycle power plants. 


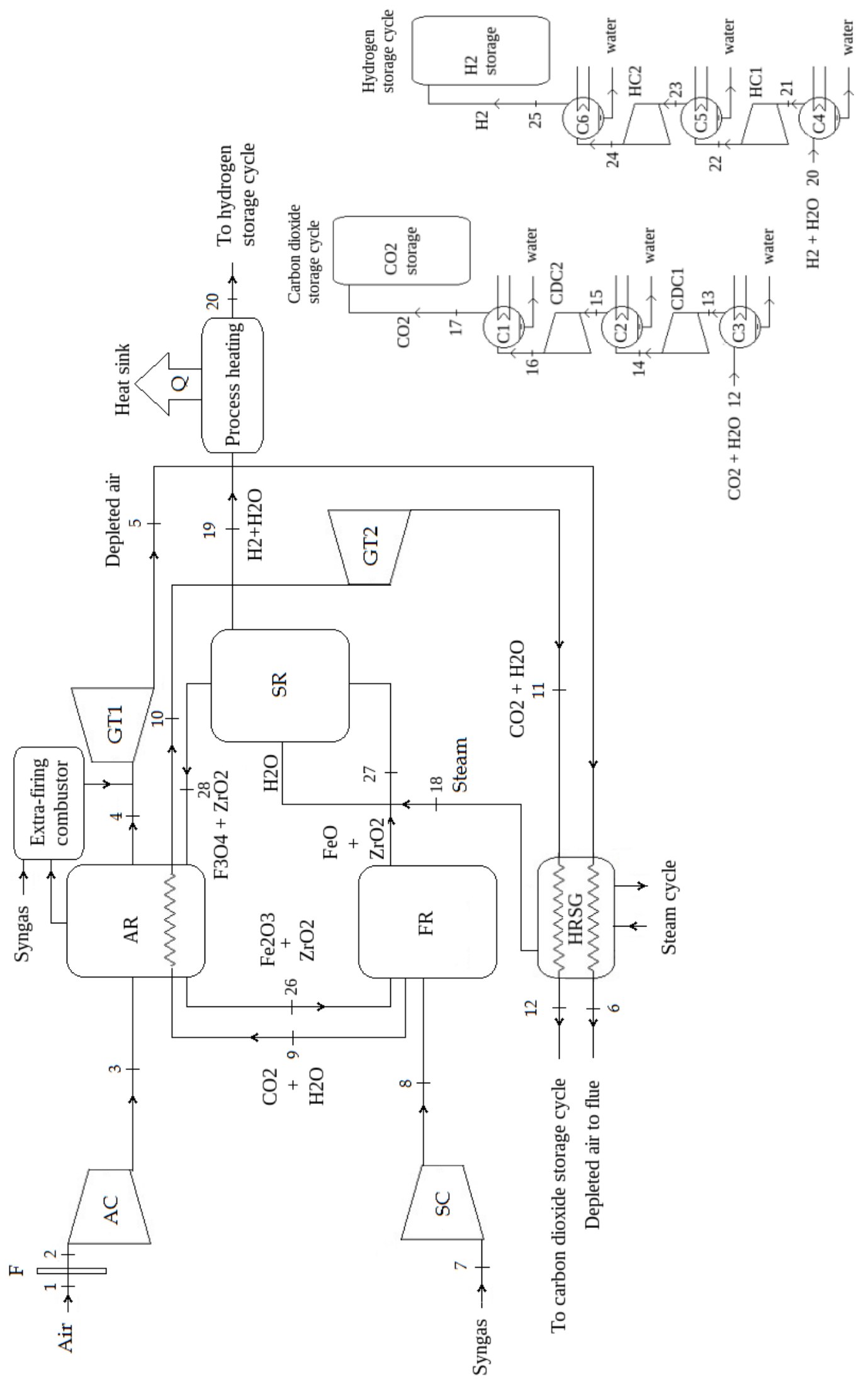

Figure 2. proposed CLHG cycle 
The behavior of this hybrid power-CLHG plant is evaluated as a function of the operating thermodynamic conditions after a previous optimization of some other thermodynamic variables. The temperature attained at the AR, which is the same as the GT1 inlet temperature (GT1IT) and the pressure of the looping reactors (denoted here by $p_{\mathrm{R}}$ ) are varied along a range of values to analyze the influence on the cycle performance.

\section{CLHG reactors}

The reactors chemical looping adopted here is a three-reactor system previously proposed for CLHG from methane [16] and from syngas [14]. It is based in a cycle of reduction-oxidation of iron oxides. The involved chemical transformations between the iron oxides and the components of syngas are:

$$
\begin{aligned}
& \text { Fuel reactor: } \quad\left\{\begin{array}{l}
\mathrm{Fe}_{2} \mathrm{O}_{3}+\mathrm{H}_{2} \rightarrow 2 \mathrm{FeO}+\mathrm{H}_{2} \mathrm{O} ; \Delta H^{\circ}\left(25^{\circ} \mathrm{C}\right)=39.59 \mathrm{~kJ} / \mathrm{mol} \\
\mathrm{Fe}_{2} \mathrm{O}_{3}+\mathrm{CO} \rightarrow 2 \mathrm{FeO}+\mathrm{CO}_{2} \quad ; \quad \Delta H^{\circ}\left(25^{\circ} \mathrm{C}\right)=-1.57 \mathrm{~kJ} / \mathrm{mol}
\end{array}\right. \\
& \text { Steam reactor: } \quad 3 \mathrm{FeO}+\mathrm{H}_{2} \mathrm{O} \rightarrow \mathrm{Fe}_{3} \mathrm{O}_{4}+\mathrm{H}_{2} \quad ; \quad \Delta H^{\circ}\left(25^{\circ} \mathrm{C}\right)=-62.94 \mathrm{~kJ} / \mathrm{mol} \\
& \text { Air reactor: } \quad 2 \mathrm{Fe}_{3} \mathrm{O}_{4}+\frac{1}{2} \mathrm{O}_{2} \rightarrow 3 \mathrm{Fe}_{2} \mathrm{O}_{3} ; \quad \Delta H^{\circ}\left(25^{\circ} \mathrm{C}\right)=-234.72 \mathrm{~kJ} / \mathrm{mol}
\end{aligned}
$$

where $\Delta H^{\circ}\left(25^{\circ} \mathrm{C}\right)$ represents the standard enthalpy of reaction at $25^{\circ} \mathrm{C}$ and standard pressure $p^{\circ} 1$ bar.

Together with the iron oxides, some extra inner material has been added to the circulating streams of oxygen carrier, since it has been reported that this may be necessary to ensure the required physical stability of the fine solid particles that contain the oxides [10]. The quantity of $0.27 \mathrm{~mol}$ of $\mathrm{ZrO}_{2}$ per mol of circulating $\mathrm{FeO}$ has been introduced for this purpose, following the same procedure as in ref. [11], which is an intermediate value between those recommended by [7] and [10]. This inert material acts does not take part in any chemical transformation, and it acts in fact just as a heat carrier between the three reactors.

\section{Chemical equilibrium and energy balance in reactors}

Assuming that enough reaction times in relation to the chemical kinetics are guaranteed, the chemical equilibrium constrain fully governs the conversion of reactants to products for reactions (1), (2) and (3):

$$
K_{a}=\exp \left(-\frac{\Delta G^{\mathrm{o}}(T)}{R T}\right)
$$

where $\Delta G^{\circ}(T)$ is the standard Gibbs' function of reaction as a function of temperature, and $K_{a}$ is the equilibrium constant of the chemical reaction, which depends on the molar composition of the reactive mixture. According to the Gibbs-Helmholtz relation $\frac{\mathrm{d}}{\mathrm{d} T} \frac{\Delta G^{\mathrm{o}}(T)}{T}=-\frac{\Delta H^{\mathrm{o}}(T)}{T^{2}}$, it is easy to see that:

$$
\frac{1}{K_{a}} \frac{\mathrm{d} K_{a}}{\mathrm{~d} T}=\frac{\Delta H^{\mathrm{o}}(T)}{R T^{2}}
$$

leading to $\mathrm{d} K_{a} / \mathrm{d} T>0$ for any endothermic reaction $\left(\Delta H^{\mathrm{o}}>0\right)$ and $\mathrm{d} K_{a} / \mathrm{d} T<0$ for any exothermic reactions $\left(\Delta H^{\mathrm{o}}<0\right)^{1}$.

\footnotetext{
${ }^{1}$ This result is usually known as Le Châtelier's Principle
} 
Fig. 3 shows the conversion ratio of $\mathrm{H}_{2}$ to $\mathrm{H}_{2} \mathrm{O}$ and $\mathrm{CO}$ to $\mathrm{CO}_{2}$ occurring in $\mathrm{FR}$ as a function of temperature. Since the reaction of hydrogen is endothermic, a reaction temperature of at least $800 \mathrm{~K}$ would be required in order to reach conversion ratios above $99 \%$. The carbon monoxide reaction is slightly exothermic, implying a small decries of its conversion ratio with temperature, but a very high value is still obtained at the highest temperatures considered here. As the mole number of gases is conserved in both reactions (1), the pressure influence on the equilibrium composition is negligible.

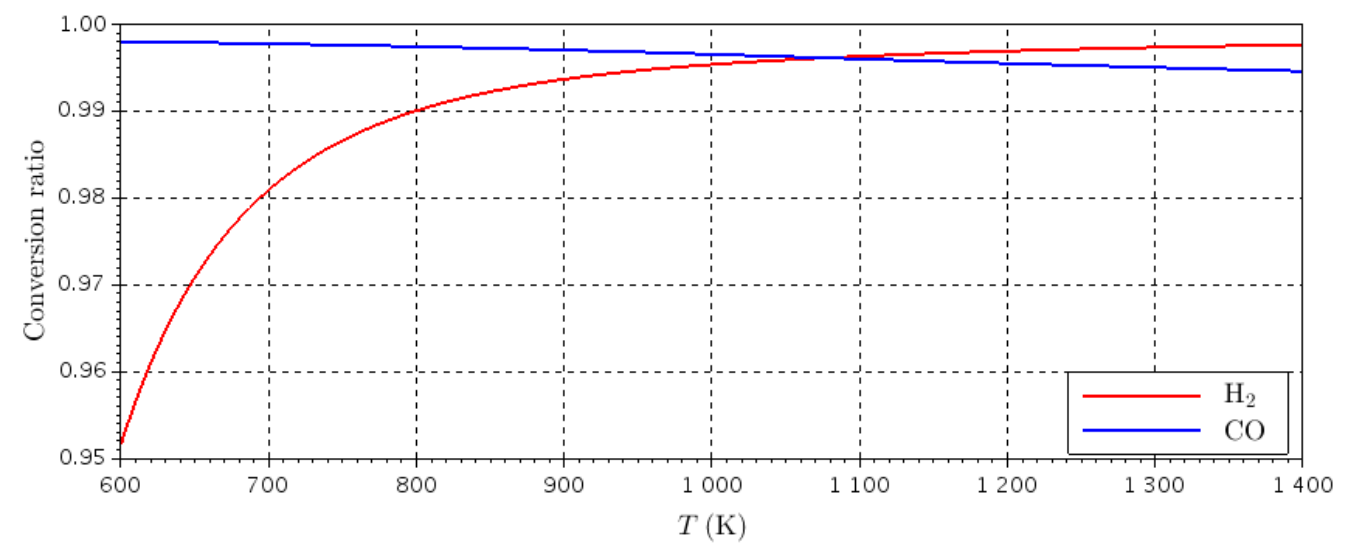

Figure $3 . \mathrm{H}_{2}$ to $\mathrm{H}_{2} \mathrm{O}$ and $\mathrm{CO}$ to $\mathrm{CO}_{2}$ conversion ratios of reactions (1) at 15 bar.

Regarding the chemical transformation at SR, the amount of hydrogen generated as a function of temperature is given in Fig 4. Similarly, almost no dependence with pressure exists. It must be remarked that, if SR temperature increases from $680 \mathrm{~K}$ to $780 \mathrm{~K}$, the molar fraction of $\mathrm{H}_{2}$ decreases from $50 \%$ to $25 \%$ approximately, i.e. it is reduced to one half. Since the number of moles of hydrogen that are generated is practically fixed by the stoichiometry of reaction (2), the number of moles of steam that have to be conducted to de SR should be doubled. This extra steam consumption would imply a penalty on the power produced by the steam turbine.

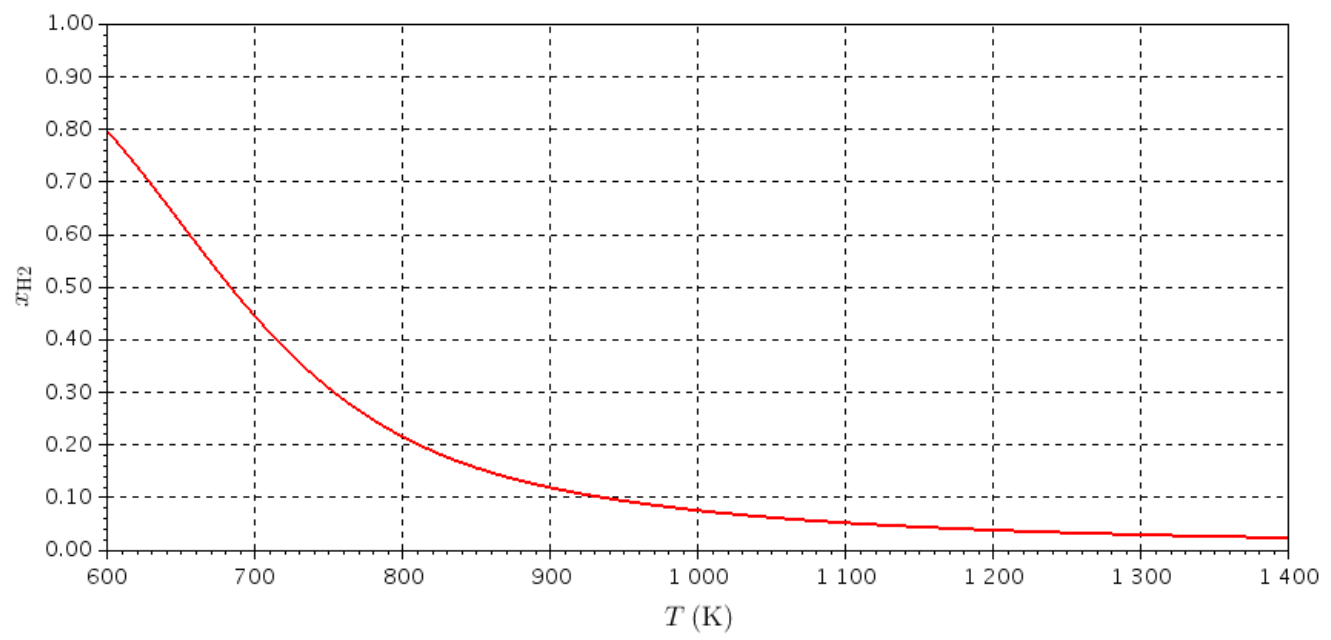

Figure 4. Molar fraction of $\mathrm{H}_{2}$ in equilibrium composition of reaction (2) at 15 bar. 
In relation with the AR, equilibrium calculations show that the chemical equilibrium never happens in this reactor in fact, as it would be only obtained for an extremely small mole fraction of oxygen. All $\mathrm{Fe}_{3} \mathrm{O}_{4}$ is fully oxidized in air.

To determine the working temperature of FR and SR and the final composition at reactors outlet, the equations of chemical equilibrium coupled with the equation of energy conservation must be solved

\section{Fuel characteristics}

The fuel selected for the study is syngas from coal gasification. In particular the American coal 'Pittsburg $\mathrm{n}^{\mathrm{o}} 8$ ' has been chosen. The composition of this syngas, after preparation, desulfuration and cleanup is given in Tab. 1 [15]. Energetic (LHV) and exergetic (chemical exergy) capabilities of the fuel are provided as well. The fuel's chemical exergy will be taken as reference for the evaluation of the power plant performance instead of its LHV, as the analyses along this paper follow the exergetic approach. More details will be discussed in a later section.

Table 1. Molar composition, LHV and chemical exergy of fuel

\begin{tabular}{lllccccccc}
\hline Fuel & $\begin{array}{l}\text { Gasification } \\
\text { substrate }\end{array}$ & $\begin{array}{l}\mathrm{CO} \\
(\%)\end{array}$ & $\begin{array}{c}\mathrm{H}_{2} \\
(\%)\end{array}$ & $\begin{array}{c}\mathrm{CO}_{2} \\
(\%)\end{array}$ & $\begin{array}{c}\mathrm{N}_{2} \\
(\%)\end{array}$ & $\begin{array}{c}\mathrm{Ar} \\
(\%)\end{array}$ & $\begin{array}{c}\mathrm{H}_{2} \mathrm{O} \\
(\%)\end{array}$ & $\begin{array}{c}\mathrm{LHV} \\
(\mathrm{kJ} / \mathrm{mol})\end{array}$ & $\begin{array}{c}e^{\mathrm{CH}} \\
(\mathrm{kJ} / \mathrm{mol})\end{array}$ \\
\hline Syngas & Pittsburgh $\mathrm{n}^{\circ} 8$ & 63.77 & 29.65 & 4.25 & 1.78 & 0.53 & 0.02 & 252.16 & 253.81 \\
\hline
\end{tabular}

\section{Extra-firing}

As can be noticed from chemical reactions (2) and (3), the oxidation of the oxygen carrier takes places in two steps. About $35 \%$ of the available heat of reaction is released in the SR and the other $65 \%$ is released in the AR. As a consequence, a lower temperature can be achieved at the gas turbines inlet and a low mass flow of air can be expanded at them. This implies that the power output generated by gas turbines is considerably lower than in a conventional gas turbine cycle. This is completely logical, since a significant part of the energy and exergy introduced to the cycle by the fuel is invested in hydrogen production. However, as it will be discussed below, the power yields are quite poor if no extra heat is delivered to the cycle.

In order to let the power plant to achieve a more acceptable specific power, it has been previously proposed to give place to a combustor between the AR and the main gas turbine GT1, e.g. [14] explores the case with syngas as fuel and [16] the case of methane. We refer to this option as extra-firing. In such a case, an additional amount of fuel is redirected to this combustor. The thermodynamic analysis of the cycle has been carried out for the original case with no extra-firing and for two different cases of extra-firing (55\% and 65\% of extra fuel consumption, denoted here by the parameter $\xi$ ). An undesired consequence of this extra burning of fuel is that the carbon dioxide generated in this direct combustion cannot be sequestrated without energy penalty. In any case, a substantial reduction would still be obtained. 


\section{METHODOLOHY}

\section{The exergy method}

The thermodynamic properties of streams at every cycle point are calculated by imposing that mass and energy balances are satisfied at all the cycle nodes. Afterwards, the evaluation of the performance of each cycle subunit and the overall power plant is carried out through the exergy balances. This is a powerful method, since a mere 'First-Law' analysis accounts only for the quantity of energy but never reaches the quantification of the "energy quality". Contrarily, the exergy method provides a 'Second-Law' analysis that allows comparing the actual performance of components, systems and processes with that of a reversible process, which is the best that could ever be obtained in accordance with both the First Law and the Second Laws of thermodynamics. Thus, it makes possible to detect and quantify the potential scope of improving of thermal and chemical processes.

The general equation for the exergy balance in a system node is given by:

$$
\sum_{i \in \text { outputs }} n_{i} e_{i}-\sum_{i \in \text { inputs }} n_{i} e_{i}=Q_{\text {ex }}-W-I
$$

In equation (6):

- $Q_{\text {ex }}(\mathrm{kW})$ is the exergy content of the heat exchanged by that node. It can be proven to be $Q_{\text {ex }}=Q-T_{0} \int \frac{\mathrm{d} Q}{T}$, where $Q$ is the heat flow rate, $T$ is the temperature at which that heat is exchanged and $T_{0}$ is ambient temperature.

- $W(\mathrm{~kW})$ stands for the mechanical power produced by that node.

- $I(\mathrm{~kW})$ is the exergy destruction rate as a result of the internal irreversibility in that node.

- $n_{i}(\mathrm{~mol} / \mathrm{s})$ represents de molar flow rate of stream $i$.

- $e_{i}(\mathrm{~kJ} / \mathrm{mol})$ is the flow exergy of stream $i$. The flow exergy can be split in two terms that account for the 'physical' and the 'chemical' parts of a stream's exergy: $e=e^{\mathrm{PH}}+e^{\mathrm{CH}}$. The physical term represents the maximum amount of power that can be theoretically obtained only by thermal and mechanical interaction with the ambient. It can be shown to be:

$$
e^{\mathrm{PH}}=\left(h-h_{0}\right)-T_{0}\left(s-s_{0}\right)
$$

where $h$ and $s$ are the specific molar enthalpy and entropy, as usual, and the subscript 0 stands for de ambient conditions of pressure and temperature. The chemical exergy $e^{\mathrm{CH}}$ represents the extra amount of power that could be obtained from a stream as a consequence of diffusive and chemical imbalances with the ambient. A detailed outline of the calculation procedure of chemical exergy of streams can be found in [15].

When the heat exchanged by a node is a heat loss to the environment or, simply it can be useful for any purpose, the exergy content of these heat exchanges can be considered as an exergy loss of this node and are included in a 'total exergy destruction' term $I_{\mathrm{t}}=I-Q_{\mathrm{ex}}$ For that cases the exergy balance (6) is simplified to:

$$
I_{\mathrm{t}}=\sum_{i \in \text { inputs }} E x_{i}-\sum_{i \in \text { outputs }} E x_{i}-W
$$


where $E x_{i}=n_{i} e_{i}$ accounts for the exergy content of stream $i$. Considering the whole power plant, the main exergy flows are depicted in Fig. 3. The only exergy input is the fuel's flow exergy, while the main exergy outputs are the net power production, the exergy of the generated $\mathrm{H}_{2}$ and the exergy content of the process heat supplied. Other minor outputs are the residual exergy of depleted air stream, the flow exergy of compressed $\mathrm{CO}_{2}$. The last term in the overall power plant exergy balance is the total exergy destruction.

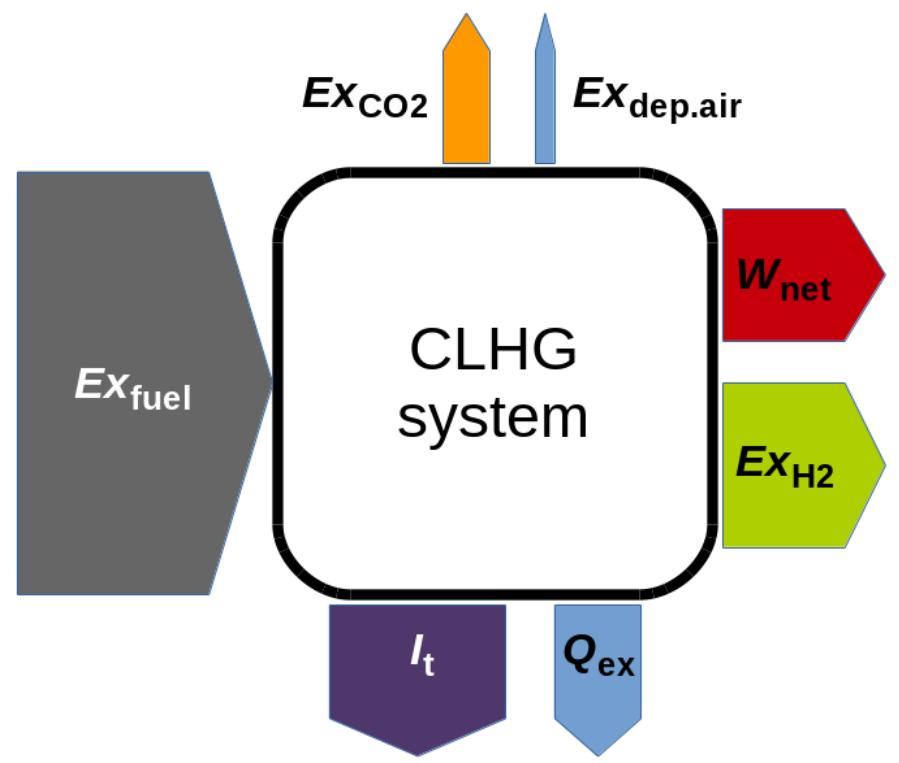

Figure 5. Exergy flows in the proposed CLHG system

The following efficiency parameters are defined:

a) Net power:

$$
\eta_{W}=\frac{W_{\mathrm{net}}}{n_{7}(1+\xi) e_{7}}=\frac{W_{\mathrm{GT} 1}+W_{\mathrm{GT} 2}+W_{\mathrm{ST}}+W_{\mathrm{CDC}}+W_{\mathrm{HC}}}{n_{7}(1+\xi) e_{7}}
$$

$W_{\text {GT1 }}$ is the power generated by GT1 subtracted the air compressor consumption; $W_{\text {GT2 }}$ is the power generated by GT2 subtracted the fuel compressor consumption and $W_{\mathrm{CDC}}$ and $W_{\mathrm{HC}}$ are the carbon dioxide and hydrogen compressors power consumptions, respectively:

$$
\begin{aligned}
& W_{\mathrm{GT} 1}=n_{2}\left(h_{2}-h_{3}\right)+n_{4}\left(h_{4}-h_{5}\right) \\
& W_{\mathrm{GT} 2}=n_{7}\left(h_{7}-h_{8}\right)+n_{10}\left(h_{10}-h_{11}\right) \\
& W_{\mathrm{CDC}}=n_{13}\left(h_{13}-h_{14}\right)+n_{15}\left(h_{15}-h_{16}\right) \\
& W_{\mathrm{HC}}=n_{21}\left(h_{21}-h_{22}\right)+n_{23}\left(h_{23}-h_{24}\right)
\end{aligned}
$$

The power production given by the ST is estimated as a fraction of the physical exergy taken from the depleted air and $\mathrm{H}_{2} \mathrm{O} / \mathrm{CO}_{2}$ streams at $\mathrm{HRSG}$, subtracting the exergy of the extraction that feeds the SR (stream 23): 


$$
W_{\mathrm{ST}}=\zeta\left[n_{5}\left(e_{5}-e_{6}\right)+n_{11}\left(e_{11}-e_{12}\right)-n_{18} e_{18}^{\mathrm{PH}}\right]
$$

In this work a value of $\zeta=0.7$ has been adopted, which is in the range of exergy efficiency of conventional steam cycles [11].

b) Hydrogen production:

$$
\eta_{\mathrm{H}_{2}}=\frac{E_{\mathrm{H}_{2}}}{n_{7}(1+\xi) e_{7}}=\frac{n_{25} e_{25}}{n_{7}(1+\xi) e_{7}}
$$

c) Process heating:

$$
\eta_{Q}=\frac{Q_{\mathrm{ex}}^{\mathrm{PH}}}{n_{7}(1+\xi) e_{7}}
$$

where $Q_{\mathrm{ex}}{ }^{\mathrm{PH}}$ is the exergy content of the heat transferred as process heating. Assuming that all the available exergy is converted, the process heating related efficiency parameter would be:

$$
\eta_{Q}=\frac{n_{19}\left(e_{19}-e_{20}\right)}{n_{7}(1+\xi) e_{7}}
$$

d) Finally an overall efficiency of the CLHG cycle with trigeneration is evaluated as:

$$
\eta_{\text {CLHGcycle }}=\eta_{W}+\eta_{\mathrm{H}_{2}}+\eta_{Q}
$$

\section{Thermodynamic modeling}

Simulations have been carried out by means of an own code developed by the authors on the basis of PATITUG library. The thermodynamic model for simulating the CLHG cycle is an extension to the one developed in [11]. It can be found in this reference a detailed discussion on the thermodynamic assumptions for the calculation of properties of gases and solids as well as a further description about PATITUG software for thermodynamic analysis.

\section{RESULTS AND DISCUSSION}

\section{Case with no extra-firing}

Cycle optimization and exergy yields. The exergetic efficiency parameters defined previously have been evaluated in a range of conditions. As commented previously, since the heating capacity of fuels is distributed in SR and AR, lower temperatures can be attained at the AR than in a combustion chamber of a conventional gas turbine system. In addition, a limited air mass flow can be compressed to produce power in gas turbine GT1. The net power output yield for the case of no extra-firing is then very low. Nevertheless, the overall exergetic efficiency of the CLHG cycle, considering the contribution of the three exergy outputs delivered as net power, hydrogen generation and process heating has found to be in general notable. Fig. 6 shows the influence of the looping reactors pressure $p_{\mathrm{R}}$ on the overall exergetic efficiency for the three TIT values under study $925 \mathrm{~K}, 962.5 \mathrm{~K}$ and $1000 \mathrm{~K}$. It was not 
possible to attain the energy balance in AR for a higher TIT than $1010 \mathrm{~K}$. The figure shows that the optimum value of $p_{R}$ for this range of TIT is between 14 and 23 bar.

The exact positions and values of the optimal points for the different TIT are given in Tab. 2 . In addition the equilibrium temperature of reactors FR and SR and the distribution of the overall exergetic efficiency on the three terms of net power, hydrogen production and process heating are given in the table.

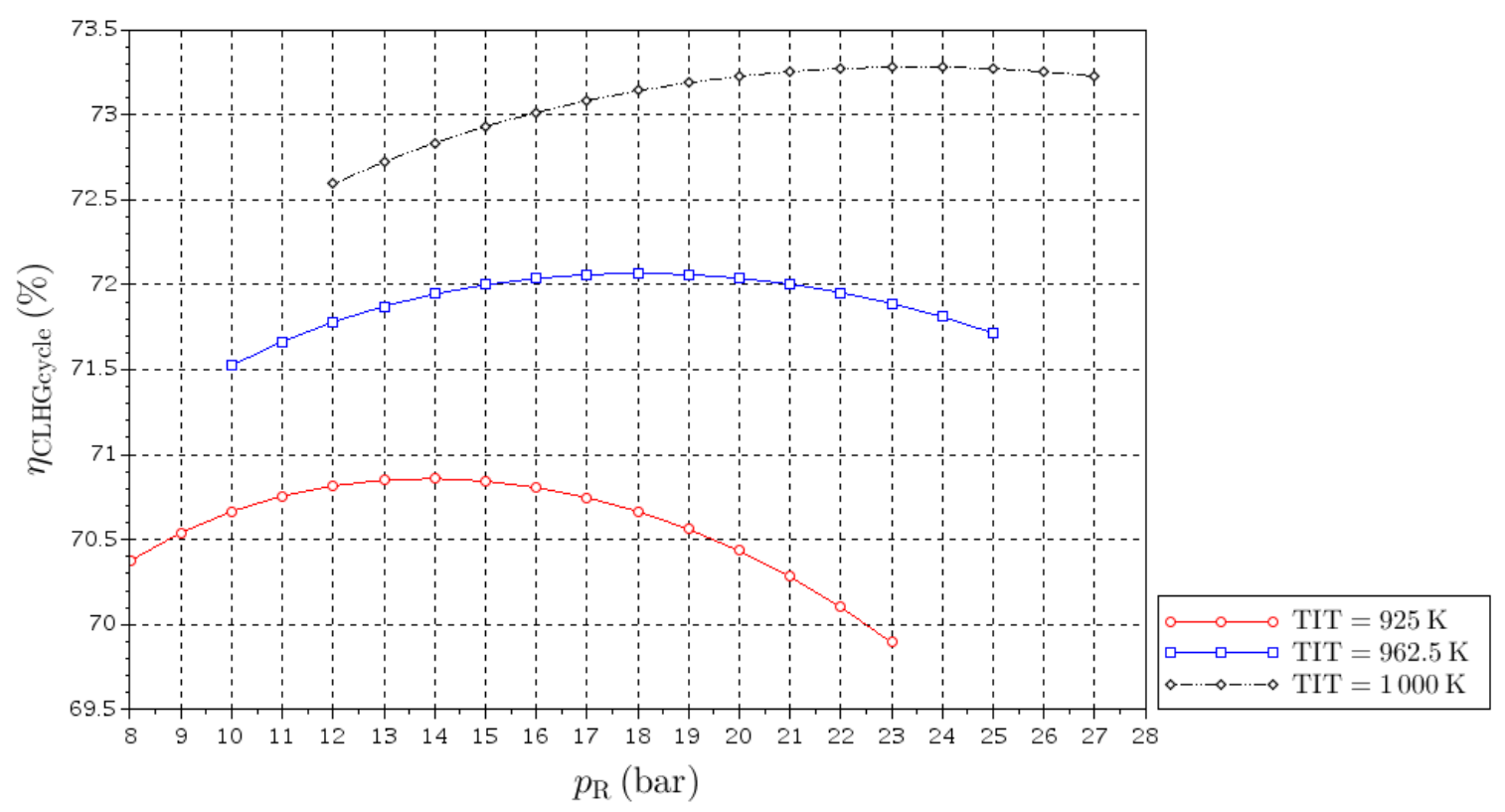

Figure 6. Overall CLHG exergy efficiency as a function of $p_{\mathrm{R}}$ for different TIT values

Table 2. Optimal working conditions and exergy efficiency parameters

\begin{tabular}{cccccccc}
\hline $\begin{array}{c}\mathrm{TIT} \\
(\mathrm{K})\end{array}$ & $\begin{array}{c}p_{\mathrm{R}} \\
(\mathrm{bar})\end{array}$ & $\begin{array}{c}T_{\mathrm{FR}} \\
(\mathrm{K})\end{array}$ & $\begin{array}{c}T_{\mathrm{SR}} \\
(\mathrm{K})\end{array}$ & $\begin{array}{c}\eta_{W} \\
(\%)\end{array}$ & $\begin{array}{c}\eta_{\mathrm{H} 2} \\
(\%)\end{array}$ & $\begin{array}{c}\eta_{Q} \\
(\%)\end{array}$ & $\begin{array}{c}\eta_{\text {CLHGcycle }} \\
(\%)\end{array}$ \\
\hline 925 & 14 & 840.5 & 680.3 & 2.83 & 60.88 & 7.15 & 70.86 \\
962.5 & 18 & 881.0 & 690.6 & 2.75 & 60.90 & 8.42 & 72.07 \\
1000 & 23 & 915.0 & 699.9 & 2.67 & 60.91 & 9.70 & 73.28 \\
\hline
\end{tabular}

In the present case (no extra-firing), the TIT temperature equals the AR operating temperature. Thus, the $\mathrm{Fe}_{2} \mathrm{O}_{3}$ /inerts stream going from the SR to the FR (stream 36 in Fig. 2) enters the FR at higher temperature as TIT increases, making the energy balance at this reactor to be satisfied at higher temperature. Equilibrium temperature at SR comes up somewhat as well.

Regarding the distribution of exergy between the three trigeneration effects, as mentioned above the power yields are very poor, and furthermore they do not even increase for a higher TIT. This is due to the fact that the mass flow of air expanded is already close to zero as TIT reaches $1000 \mathrm{~K}$. The exergy assigned to hydrogen production is the most important term. Moreover, it is almost constant, since one mole of hydrogen is generated for every three 
moles of circulating $\mathrm{FeO}$ according to (2), and there are very approximately ${ }^{2}$ two moles of circulating $\mathrm{FeO}$ for every mole of $\mathrm{H}_{2}$ and $\mathrm{CO}$ in fuel, which is a constant value. The exergy content of process heating increases with TIT for two reasons: first, SR equilibrium temperature is higher, and second, the mass flow of the $\mathrm{H}_{2} \mathrm{O} / \mathrm{H}_{2}$ stream increases as well, since more input steam is required for satisfying the chemical equilibrium condition (see Fig. 4).

Tab. 3 quantifies and compares the overall exergy input and output flows of the whole CLHG cycle depicted in Fig. 5. The power term has been split in the different terms that constitute it, i.e. power generated from gas turbines and from steam turbine and power consumption of $\mathrm{CO}_{2}$ and $\mathrm{H}_{2}$ compressors. It can been remarked that together with the useful exergy streams of power, hydrogen and process heating, also the carbon dioxide stream compressed up to its storage pressure contains a significant amount of exergy, of the order of $8 \%$ of fuel's exergy.

Table 3. Overall exergy balance in the CLHG cycle. Data given as a fraction of fuel's exergy $n_{7} e_{7}$ in $\%$.

\begin{tabular}{|c|c|c|c|c|c|c|c|c|c|}
\hline $\begin{array}{c}\mathrm{TIT} \\
(\mathrm{K})\end{array}$ & $\begin{array}{c}W_{\mathrm{GT} 1+2} \\
(\%)\end{array}$ & $\begin{array}{c}W_{\mathrm{ST}} \\
(\%)\end{array}$ & $\begin{array}{c}-W_{\mathrm{CDC}} \\
(\%)\end{array}$ & $\begin{array}{c}-W_{\mathrm{HC}} \\
(\%)\end{array}$ & $\begin{array}{c}E_{\mathrm{H} 2} \\
n_{25} e_{25}\end{array}$ & $\begin{array}{c}E_{\mathrm{CO} 2} \\
n_{17} e_{17}\end{array}$ & $\begin{array}{c}E_{\mathrm{dep} . a i r} \\
n_{6} e_{6}\end{array}$ & $\begin{array}{c}Q_{\mathrm{ex}}^{\mathrm{PH}} \\
(\%)\end{array}$ & $\begin{array}{c}I_{\mathrm{t}} \\
(\%)\end{array}$ \\
\hline 925 & 5.77 & 2.66 & 4.09 & 1.50 & 60.89 & 8.15 & 0.30 & 7.15 & 20.67 \\
\hline 962.5 & 5.86 & 2.25 & 4.09 & 1.27 & 60.90 & 8.12 & 0.24 & 8.42 & 19.57 \\
\hline 1000 & 5.99 & 1.82 & 4.08 & 1.06 & 60.91 & 8.11 & 0.19 & 9.70 & 18.42 \\
\hline
\end{tabular}

Exergy flows: Grasmann diagram. An intuitive manner to present a more detailed exergy analysis of the cycle is a Grassmann diagram. This kind of charts indicates the exergy flows connecting the different subunits of the cycle, giving a component by component exergy balance. It is usually expressed in a way that the exergy content of every stream is proportional width of the arrow that represents it. Fig. 7. gives the Grassmann diagram of the CLHG cycle with no extra-firing for a TIT value of $1000 \mathrm{~K}$ and optimal conditions for this case according to data in Tab. 2. In Fig. 7 the total exergy loss $I_{\mathrm{t}}$ in every component is given inside that component's box.

\section{Cases with extra-firing}

Although the overall cycle efficiency obtained for the case with no extra-firing is quite significant, considering the combination of the three useful effect, it is clear that, for the purpose of a trigeneration system, to provide a larger specific power output is of interest.

To investigate the influence of extra-firing on the exergy balances, four cases have been analyzed. TIT has been increased to $1350 \mathrm{~K}$ and $1500 \mathrm{~K}$ and the extra-firing parameter $\xi$ has been set to $55 \%$ and $65 \%$.

Cycle optimization and exergy yields. As shown by Fig. 8, the net power output as a fraction of fuel's exergy reaches more attractive figures for the extra-firing cases under study. The curves depicted in the figure present a maximum of the specific power for $p_{\mathrm{R}}$ between 26 and 30 bar. For the highest $\xi$ more net power efficiency is attained. It is also remarkable that for the range of $\xi$ considered the power output do not increase with TIT: from the point of view

\footnotetext{
2 This is not completely exact, as the conversion ratio of reactions (1) do not reach the value one exactly. Nevertheless both of them are above 0.99 for the temperature attained at FR (see Fig. 3).
} 
of power yield it would be preferred to operate at a lower TIT giving place to a larger mass flow across the gas turbine GT1.

The overall cycle efficiency is given in Fig. 9. Contrarily to the net power efficiency, it is observed a correlation between the overall exergy efficiency and TIT, as it would be expected from theoretical considerations. In addition, the cycle efficiency is reduced when the extrafiring parameter increases, due to the extra exergy destruction associated with the irreversibility in the combustor, where a direct combustion takes place. Thus, it is clear that the setting that beneficiates the power output is not the optimal from the overall exergy efficiency point of view, and vice versa. 


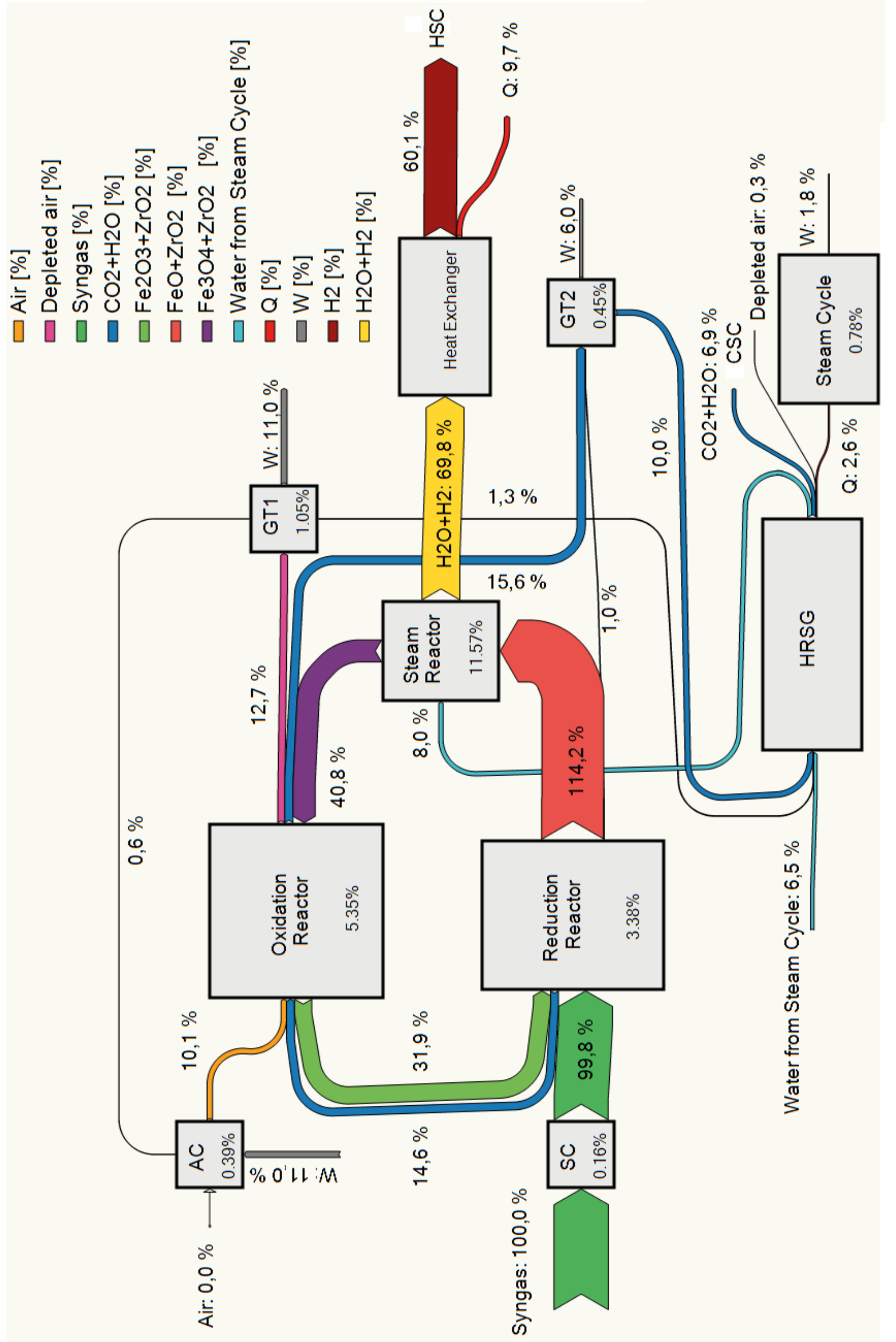

Figure 7. Grassmann diagram of exergy flows. Optimal operating condition for TIT $=1000 \mathrm{~K}$. 


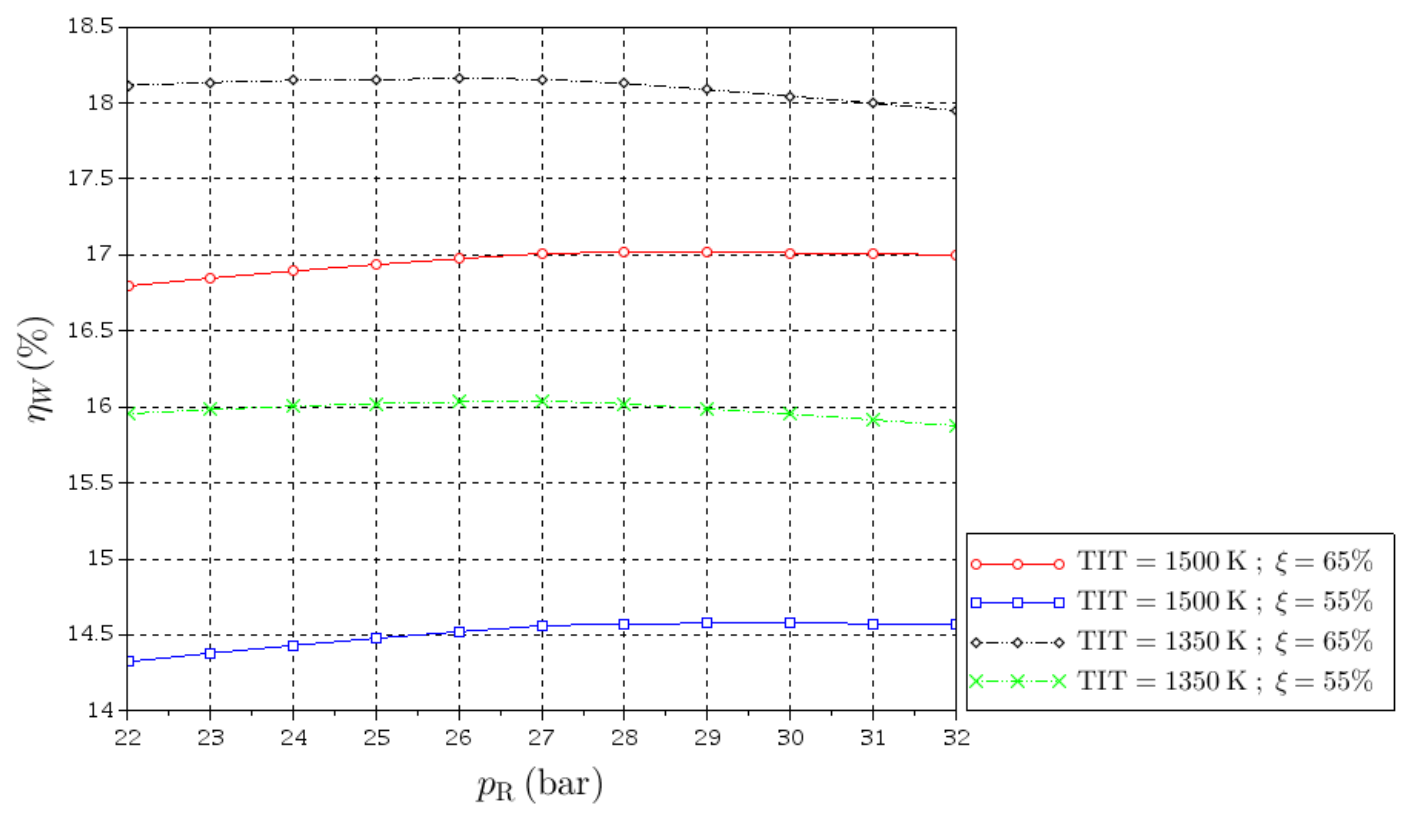

Figure 8. Power generation exergy efficiency as a function of $p_{\mathrm{R}}$ for different TIT values for the cases with extra-firing

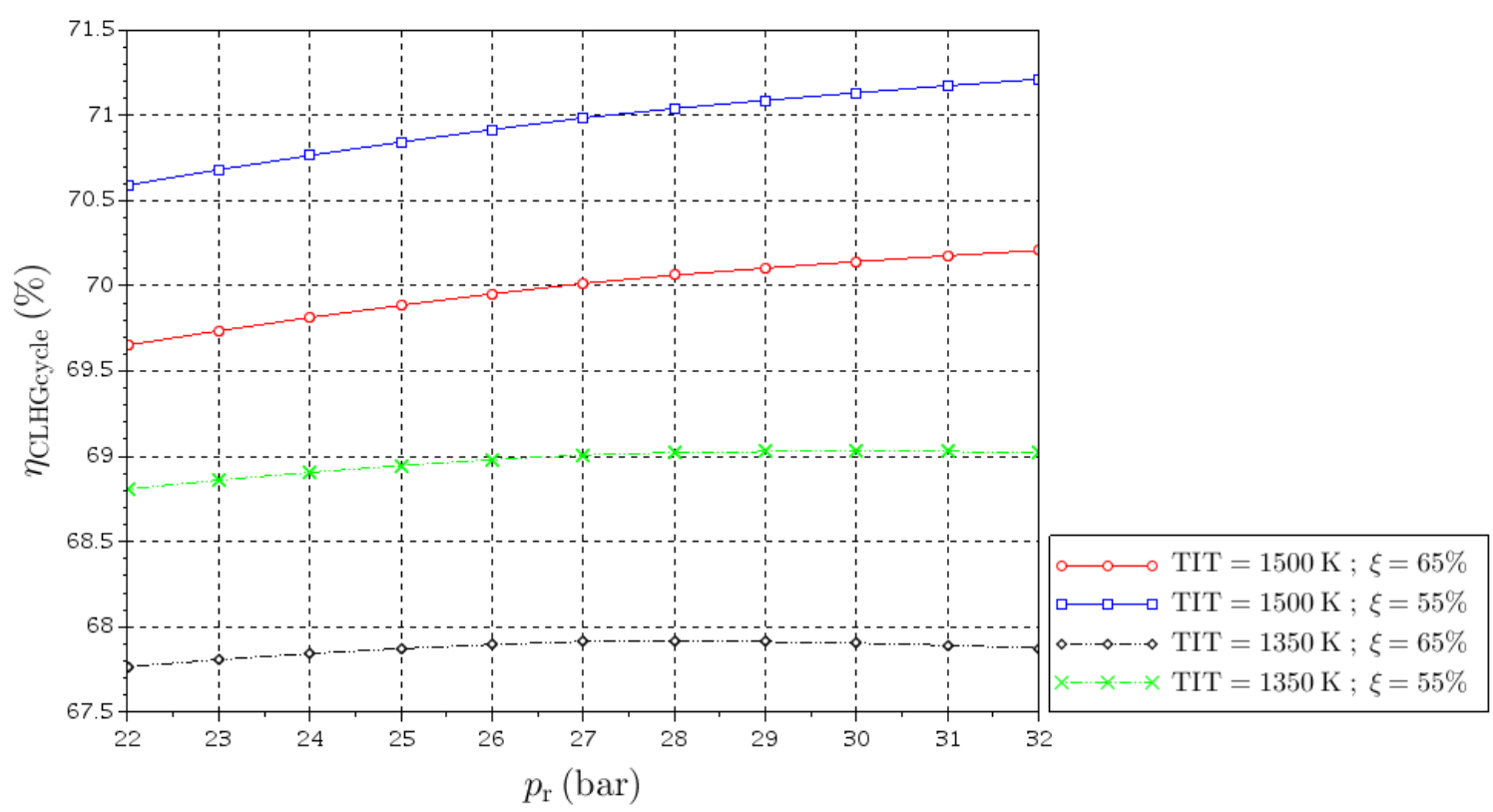

Figure 9. Overall CLHG exergy efficiency as a function of $p_{\mathrm{R}}$ for different TIT values for the cases with extra-firing

Tabs. 4 and 5 give the optimal working conditions and the overall exergy flows of the CLHG cycle for the extra-firing cases under study. Temperature in FR is strongly increased in correlation with TIT, and temperature in SR is also quite higher. The implication is an important extra process heating availability. In general, the main effect of extra-firing, to a 
greater or lesser extent, is a more equitable sharing of the exergy content of the three useful effects of trigeneration, assuming a certain diminution in the overall cycle efficiency. The last column of Tab. 5 gives the total exergy loss in the cycle, mainly accounting for the extra exergy destruction in the combustion chamber. The residual exergy content of the compressed carbon dioxide stream is lower with extra-firing, since in this cases only a fraction of the carbon contained by the fuel can be sequestrated.

Table 4. Optimal working conditions and exergy efficiency parameters for the cases with extra-firing

\begin{tabular}{ccccccccc}
\hline $\begin{array}{c}\text { TIT } \\
(\mathrm{K})\end{array}$ & $\begin{array}{c}\xi \\
(\%)\end{array}$ & $\begin{array}{c}p_{\mathrm{R}} \\
(\mathrm{bar})\end{array}$ & $\begin{array}{c}T_{\mathrm{FR}} \\
(\mathrm{K})\end{array}$ & $\begin{array}{c}T_{\mathrm{SR}} \\
(\mathrm{K})\end{array}$ & $\begin{array}{c}\eta_{W} \\
(\%)\end{array}$ & $\begin{array}{c}\eta_{\mathrm{H} 2} \\
(\%)\end{array}$ & $\begin{array}{c}\eta_{Q} \\
(\%)\end{array}$ & $\begin{array}{c}\eta_{\text {CLHGcycle }} \\
(\%)\end{array}$ \\
\hline 1350 & 55 & 30 & 1216.6 & 759.70 & 16.05 & 39.29 & 13.68 & 69.02 \\
1350 & 65 & 28 & 1215.1 & 759.39 & 18.17 & 36.91 & 12.83 & 67.91 \\
1500 & 55 & 32 & 1357.3 & 780.58 & 14.59 & 39.28 & 17.27 & 71.14 \\
1500 & 65 & 32 & 1357.3 & 780.58 & 17.02 & 36.90 & 16.14 & 70.06 \\
\hline
\end{tabular}

Table 5. Overall exergy balance in the CLHG cycle for the cases with extra-firing. Data given as a fraction of fuel's exergy $n_{7}(1+\xi) e_{7}$ in $\%$.

\begin{tabular}{|c|c|c|c|c|c|c|c|c|c|c|}
\hline $\begin{array}{c}\mathrm{TIT} \\
(\mathrm{K})\end{array}$ & $\begin{array}{c}\xi \\
(\%)\end{array}$ & $\begin{array}{c}W_{\mathrm{GT} 1+2} \\
(\%)\end{array}$ & $\begin{array}{c}W_{\mathrm{ST}} \\
(\%)\end{array}$ & $\begin{array}{c}-W_{\mathrm{CDC}} \\
(\%)\end{array}$ & $\begin{array}{c}-W_{\mathrm{HC}} \\
(\%)\end{array}$ & $\begin{array}{c}E_{\mathrm{H} 2} \\
n_{25} e_{25}\end{array}$ & $\begin{array}{c}E_{\mathrm{CO} 2} \\
n_{17} e_{17}\end{array}$ & $\begin{array}{c}E_{\mathrm{dep} . a i r} \\
n_{6} e_{6}\end{array}$ & $\begin{array}{c}Q_{\mathrm{ex}}^{\mathrm{PH}} \\
(\%)\end{array}$ & $\begin{array}{c}I_{\mathrm{t}} \\
(\%)\end{array}$ \\
\hline 1350 & 55 & 14.06 & 5.21 & 2.63 & 0.59 & 39.29 & 5.24 & 0.36 & 13.68 & 25.38 \\
\hline 1350 & 65 & 15.30 & 5.91 & 2.47 & 0.57 & 36.91 & 4.92 & 0.42 & 12.83 & 26.75 \\
\hline 1500 & 55 & 13.10 & 4.65 & 2.63 & 0.53 & 39.28 & 5.26 & 0.22 & 17.27 & 23.38 \\
\hline 1500 & 65 & 14.56 & 5.47 & 2.47 & 0.54 & 36.90 & 4.94 & 0.27 & 16.14 & 24.73 \\
\hline
\end{tabular}

Exergy flows: Grasmann diagram. The Grassmann diagram of the CLHG cycle for the case with TIT $=1500$ and $\xi=0.55$ is shown in Fig. 10.

\section{CONCLUSION}

The performance of a syngas-fueled CLHG cycle with coproduction of power, hydrogen and process heating with carbon dioxide sequestration has been evaluated by means of the exergy method. The optimal operating conditions and equilibrium temperature of the involved subunits has been calculated considering the overall exergy efficiency as the parameter to be maximized. The results reveal a very attractive potential of chemical-looping combustion for this triple generation with very notable efficiency.

In particular, the following conclusions can be extracted from the study conducted here:

- Overall efficiency of the cycle reaches figures of around 67-73\%, considering that all process heating potential is really delivered.

- Equilibrium temperature at the looping reactors has been found to ensure a high conversion factor in the chemical transformations involved, particularly in the case of the FR.

- When no extra-firing is carried out, the overall efficiency is the highest possible, but a very low power yield is obtained. 


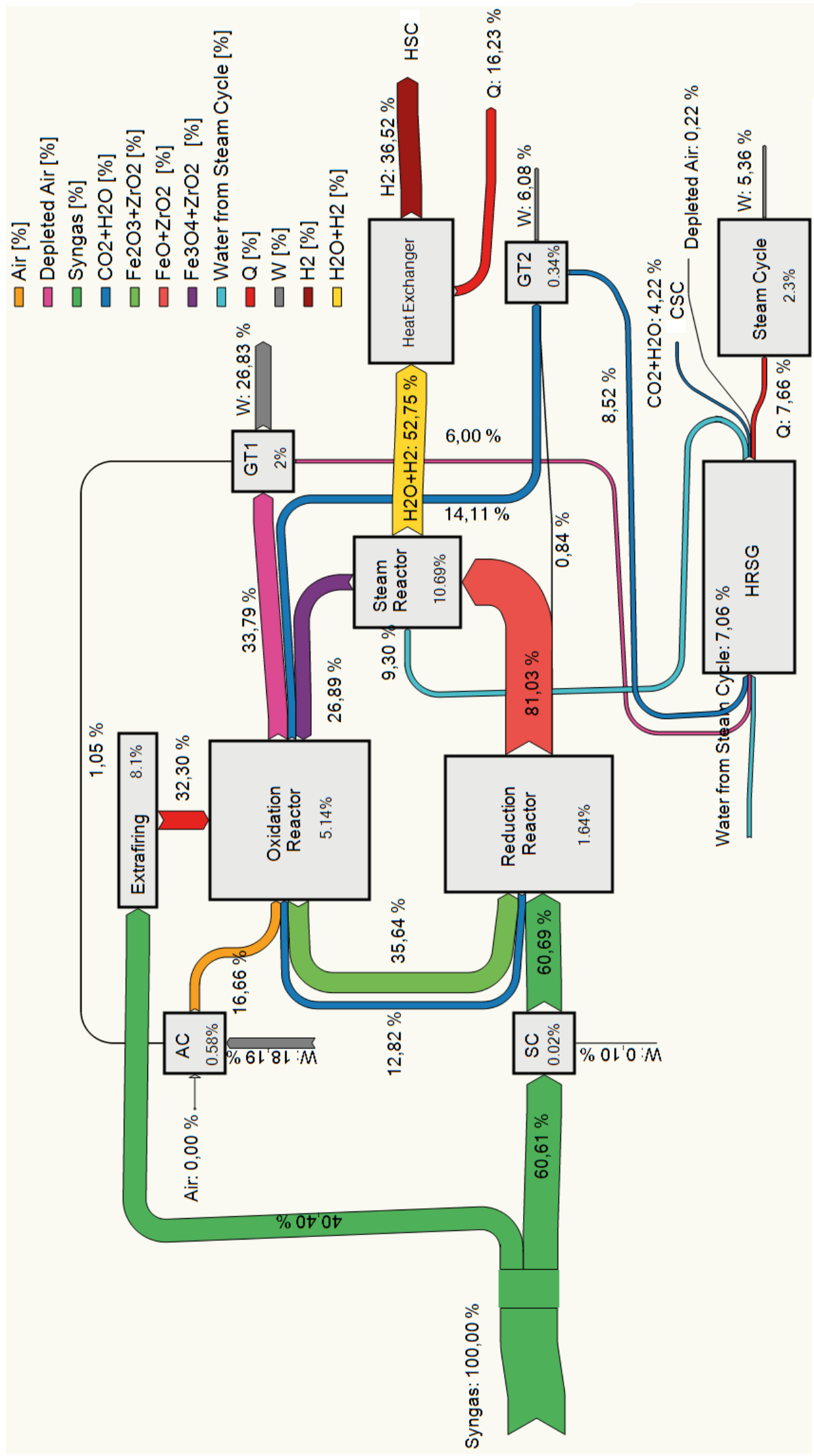

Figure 10. Grassmann diagram of exergy flows. Optimal operating condition for TIT $=1500 \mathrm{~K}$ and $\xi=55 \%$. 
- Extra-firing allows increasing TIT and mass flow across the main gas turbine. The part of fuels exergy transformed in power increases and also a more equitant share of the exergy outputs is obtained. However, the overall exergy efficiency is penalized due to the additional irreversibility induced by the direct combustion of some fuel.

- The optimal working conditions from the point of view of maximizing the specific power for a given TIT and extra-firing value are not the same than those that optimize the overall efficiency.

\section{NOMENCLATURE}

Symbol

$W$ : Mechanical power

$W_{\text {net: }}$ Net power production

$Q$ : Heat

$Q_{\text {ex}}$ : Exergy content of heat

I: Exergy destruction

$I_{\mathrm{t}}$ : Total exergy loss

Ex: Exergy content of a stream

T: Temperature

$p_{\mathrm{R}}$ : Pressure at the looping reactors

$p^{\text {o: }}$ : Standard pressure

$R$ : Ideal gas constant

$n$ : Molar flow rate

$h$ : Specific molar enthalpy

$s$ : Specific molar entropy

$e$ : Flow exergy

$e^{\mathrm{PH}}$ : Physical flow exergy

$e^{\mathrm{CH}}$ : Chemical flow exergy

$\Delta H^{\mathrm{o}}$ : Standard enthalpy of reaction

$\Delta G^{\mathrm{o}}$ : Standard Gibb's function of reaction

$K_{a}$ : Chemical equilibrium constant

$x$ : Molar fraction
Greek letter

$\xi$. Extra-firing parameter

$\zeta:$ Exergetic efficiency of steam cycle

$\eta_{W}$ : Net power exergetic efficiency

$\eta_{\mathrm{H} 2}$ : Hydrogen production exergetic efficiency

$\eta_{Q}$ : Process heating exergetic efficiency

$\eta_{\text {CLHGcycle: Overall CLHG cycle exergetic }}$ efficiency

\section{Subscripts}

GT1: Gas turbine 1

GT2: Gas turbine 2

ST: Steam turbine

CDC: Carbon dioxide compressors

HC: Hydrogen compressors

FR: Fuel reactor

SR: Steam reactor

0 : Ambient conditions

Superscripts

PH: Process heating

\section{REFERENCES}

1. Abu-Khader M. M., Recent progress in $\mathrm{CO}_{2}$ capture/sequestration: a review. Energy Sources Part A: Recovery, Utilization, Environ Effects, Vol. 28, No. 3, pp 1261-1279, 2006.

2. Chiesa P., Consonni S., Natural gas fired combined cycles with low $\mathrm{CO}_{2}$ emissions. J Eng Gas Turb Power, Vol. 122, No. 3, pp 429-436, 2000.

3. Lozza G., Chiesa P., Natural gas decarbonization to reduce low $\mathrm{CO}_{2}$ emission from combined cycles. part a: Partial oxidation - part b: Steam-methane reforming. J Eng Gas Turb Power, Vol. 124, No. 3, pp 82-95, 2002.

4. Ziębik A., Gładysz P., Analysis of cumulative energy consumption in an oxy-fuel combustion power plant integrated with a $\mathrm{CO}_{2}$ processing unit. Energy Conv Manag, Vol. 87, pp 13051314, 2014.

5. Ishida M., Jin H., A new advanced power-generation system using chemical-looping combustion. Energy, Vol. 19, No. 4, pp 415-424, 1994.

6. Ishida M., Jin H., Chemical looping combustion power generation plant system. United States Patent, No. 5447024, 1995. 
7. Consonni S., Lozza G., Pelliccia G., Rossini S., Saviano F., Chemical-looping combustion for combined cycles with CO2 capture. J Eng Gas Turb Power,Vol 128, No. 3, pp 525-534, 2006.

8. Peltola P., Ritvanen J., Tynjălă T., Hyppănen T., Model-based evaluation of a chemical looping combustion plant for energy generation at a pre-commercial scale of $100 \mathrm{MW}$ th. Energy Conv Manag, Vol. 76, pp 323-331, 2013.

9. Zhang X., Han W., Hong H., Jin H., A chemical intercooling gas turbine cycle with chemicallooping combustion. Energy, Vol. 34, No. 12, pp 2131-2136, 2009.

10.Anheden M., Svedberg G., Exergy analysis of chemical-looping combustión systems. Energy Conv Manag, Vol. 39, No. 16-18, pp 1967-1980, 1998.

11.Jiménez Á., López I., González C., Nieto R., Rodríguez J., Energetic analysis of a syngasfueled chemical-looping combustion combined cycle with integration of carbon dioxide sequestration. Energy, Vol. 76, pp 694-703, 2014.

12.Jiménez Á., López I., González C., Rodríguez J., Nieto R., Simulation of an integrated gasification combined cycle with chemical-looping combustion and carbon dioxide sequestration. Energy Conv Manag, Vol. 104, pp 170-179, 2015.

13.Zhang X., Li S., Hong H., Jin H., A hydrogen and oxygen combined cycle with chemicallooping combustion. Energy Conv Manag, Vol. 85, pp 701-708, 2014.

14.Ozcan H., Dincer I., Thermodynamic analysis of a combined chemical looping-based trigeneration system. Energy Conv Manag, Vol. 85, pp 477-487, 2014.

15.Urdiales Á., Jiménez Á., Rodríguez J., Nieto R., Exergy analysis of a syngas-sueled combined cycle with chemical-looping combustion and $\mathrm{CO}_{2}$ sequestration, Proceedings of the $2^{\text {nd }}$ International Electronic Conference on Entropy and its Applications, November 15-30, 2015.

16.Chiesa P., Lozza G., Malandrino A., Romano M., Piccolo V., Three-reactors chemical looping process for hydrogen production. International Journal of Hydrogen Energy, Vol. 33, pp 2233-2245, 2008. 